\title{
La modalidad lingüistica andaluza en la serie de ficción $L a$ Peste y su repercusión mediática
}

\author{
Marta León-Castro Gómez \\ Profesora de Lengua Española \\ Departamento de Lengua Española, Lingüística y Teoría de la Literatura \\ Universidad de Sevilla (España) \\ E-mail: mleoncastro@us.es
}

\begin{abstract}
LA MODALIDAD LINGÜÍSTICA ANDALUZA EN LA SERIE DE FICCIÓN LA PESTE Y SU REPERCUSIÓN MEDIÁTICA
\end{abstract}

\begin{abstract}
RESUMEN: Nos planteamos, por un lado, analizar desde un punto de vista sociolingüístico los personajes de esta serie de ficción, y por otro, comprobar cuál ha sido la repercusión mediática y la percepción real de los espectadores a través de Twitter. Se ha tomado como muestra el habla de los once personajes con mayor presencia en la trama; asimismo, se han registrado 202 tuits con la etiqueta "\#LaPeste andaluz". Comprobamos que la mayoria de los personajes principales y secundarios se expresan con rasgos de pronunciación muy extendidos en la región andaluza, socialmente bien valorados, que no obstaculizan la comunicación. Asimismo, las críticas en Twitter, minoritarias con respecto a las defensas de la pronunciación andaluza, se centran en la mala vocalización y el sonido. Sin embargo, los medios de comunicación ponen el foco en el acento como causa fundamental de la ininteligibilidad y fomentan los tópicos andaluces presentes en el imaginario colectivo.
\end{abstract}

PAlABRAS Claves: La Peste; modalidad lingüistica andaluza; sociolingüística; Twitter; medios de comunicación.

SUMARIO: 1. Introducción. 2 . Corpus y metodologia. 3. Estudio y resultados del empleo del modelo andaluz en la serie. 4. Estudio y resultados de su repercusión mediática. Consideraciones finales.

Fecha de Recepción Fecha de Revisión Fecha de Aceptación Fecha de Publicación
THE ANDALUSIAN LINGUISTIC MODALITY IN THE FICTION SERIES LA PESTE AND ITS MEDIA REPERCUSSION

ABSTRACT: This article aims to analyze the characters played in the TV fiction series "La Peste" from a sociolinguistic point of view and to determine the impact it had on the media, as well as the real perception of the spectators, shared on Twitter. We collected as samples the speech used by the main eleven characters in the series; and we have registered 202 tweets with the hashtag "\#LaPeste andaluz". We noticed that most of the first and second role actors have peculiar pronunciation characteristics which are widely spread in the Andalusian region, are socially well appreciated, and not hindering the communication. We also observed that the critics received on Tweeter against (although in less number than the ones in favor) are mainly focused on bad vocalization and its sound; meanwhile, the Media points out the accent as the root cause of unintelligibility by supporting the clichés about Andalusian accent.

KEY WORDS: La Peste; Andalusian linguistic modality; Sociolinguistic; Twitter, media.

SUMMARY: 1. Introduction. 2 . Corpus and methodology. 3. Study and results of the Andalusian model use in the series. 4. Study and results of the media repercussion over La Peste. 5. Concluding remarks.

\section{LA MODALITE LINGUISTIQUE ANDALOUSE DANS LA SERIE DE FICTION LA PESTE ET SA REPERCUSSION MEDIATIQUE}

RÉSUMÉ: Cette étude propose d'étudier les personnages de "La Peste " d'un point de vue sociolinguistique et de déterminer la répercussion et la perception réelle des spectateurs sur Twitter. Elle s'appuie sur des extraits de parole des onze personnages principaux de cette série ; de la même façon, on a recueilli 202 tweets avec l'étiquette "\#LaPeste andaluz". Dernièrement, on a observé que la plus grande partie de personnages principaux et secondaires s'expriment en utilisant des traits de prononciation très répandus dans la région andalouse, estimés socialement qui n'empêchent point la communication. On a aussi constaté que les critiques concernant la série sur Twitter (moins que celles qui sont à faveur de la prononciation andalouse) sont concentrées en fait sur la mauvaise vocalisation et le son. Cependant, la presse attribut à l'accent la cause fondamentale de l'inintelligibilité et promeut les clichés andalous.

MOTS CLÉS: La Peste; modalité linguistique andalouse; Sociolinguistique; Twitter; presse

SOMMAIRE: 1 . Introduction. 2 Corpus et méthodologie. 3. Étude et résultats de l'emploi du modèle andalou dans la série. 4. Étude et résultats de la répercussion médiatique sur La Peste. 5. Remarques finales 


\title{
La modalidad lingüistica andaluza en la serie de ficción $L a$ Peste y su repercusión mediática ${ }^{1}$
}

\author{
MARTA LEÓN-CASTRO GÓMEZ
}

\section{INTRODUCCIÓN}

El andaluz es una modalidad lingüística del español peninsular, que posee "un perfil lingüístico propio y diferenciable, dotado de rasgos meridionales que en cierta medida son compartidos por muchas hablas americanas" (Carbonero 2003: 109) y que se diferencia claramente del español septentrional.

Es muy fácilmente reconocible fuera de las fronteras de Andalucía, especialmente por sus rasgos fonéticos. Sin embargo, la imagen que se tiene de ella es en realidad parcial y desvirtuada, ya que, por un lado, "se encuentra empañada por falsos tópicos y estereotipos, con frecuencia históricamente infundados"; y, por otro, porque los prejuicios que se han ido extendiendo y consolidando constituyen un obstáculo para su descripción y valoración objetivas (Narbona 2003: 9).

En la actualidad sigue siendo el eje de referencia la pronunciación del norte y centro de la Península (al menos para la norma del continente europeo), por lo que los medios de comunicación tienden a ofrecer esa fonética norteña en la lengua culta de presentadores de informativos, tertulianos, reporteros, etc. (incluso, en muchos casos, cuando se trata de profesionales andaluces) y reservan la andaluza para los espacios de entretenimiento y los personajes humorísticos de películas y series de ficción.

Existe "una consideración popular de que el andaluz es un castellano mal hablado o una forma incorrecta de hablar español" (Carbonero 2003, 127). Sin embargo, no se trata de una creencia reciente, sino que debemos remontarnos en realidad a su origen, pues ya entonces se concebía como una variedad menos prestigiosa. "Las vicisitudes históricas de nuestra modalidad propiciaron que se valorara negativamente, siempre por debajo de lo que se ha denominado el modelo norteño" que se hablaba en la Corte (desde donde se imponía la norma) y que se asociaba a la ejemplaridad social (León-Castro 2016: 1584).

Así pues, lejos de considerarse la evolución natural del castellano en una zona geográfica distinta, se entendió como un desvío de la norma toledana ${ }^{2}$. La evolución es una característica esencial de las lenguas, una manifesta-

\footnotetext{
${ }^{1}$ Este artículo hace parte de las actividades del grupo de investigación Sociolingüística andaluza (HUM 141) de la Universidad de Sevilla.

${ }^{2}$ Aunque existen documentos anteriores, son conocidas las valoraciones negativas de Juan Valdés (Diálogo de la lengua, 1533) a Andalucía, "donde la lengua no stá muy pura", especialmente dirigidas al habla del humanista sevillano Antonio Nebrija.
} 
ción evidente de que están vivas y van cambiando para adaptarse a las necesidades de cada comunidad de hablantes, por lo que no debe entenderse como corrupción.

No obstante, hoy sigue concibiéndose el modelo de ejemplaridad para la norma peninsular el que se habla en la zona centro-norte, especialmente el habla de la capital madrileña ${ }^{3}$. Como consecuencia, otras modalidades no se tienen por correctas al compararse con ese "castellano oficial". Se trata de un planteamiento erróneo, ya que implica considerar los rasgos propios de una modalidad lingüística desde la perspectiva de otra, "con la que lógicamente no se corresponde en todos sus rasgos, porque tiene lo suyos propios" (Carbonero 2003: 128).

Además de la dependencia económica y cultural de otras regiones, han influido otros factores de índole sociopolitica en la valoración cambiante del andaluz a lo largo de los siglos, ya que las connotaciones que se asocian a una determinada habla dependen en gran medida de la visión que se tenga de la región correspondiente. Según explica el profesor Cano Aguilar:

Cuando Andalucía tenía una fuerza económica notable por su relación con América, en los siglos $\mathrm{XVI}^{4}$ y XVII, no se decían las cosas que se empezaron a decir en el siglo XIX ${ }^{5}$, cuando la región entra en decadencia económica y queda asociada a los caciques, los latifundistas, los espadones, los flamencos... ("La polémica 'ehtá servia", Ideal, $15 / 01 / 09)$.

Por otro lado, es precisamente en el siglo XIX cuando las obras de los viajeros europeos, impregnadas del Romanticismo de la época, ofrecen una imagen distorsionada de Andalucía, que acentúa su carácter exótico y pintoresco, que ha fomentado algunos de los tópicos que se le atribuyen y que aún hoy persisten.

Hemos de añadir un último factor, esta vez en el ámbito educativo: el alto grado de analfabetismo que presentaba la comunidad autónoma hasta los años 70 del siglo XX y que hoy ha sido sustituido por los malos resultados escolares ${ }^{6}$ en comparación con el resto de España y más todavía dentro del contexto europeo.

\footnotetext{
${ }^{3}$ Los datos del PRECAVES XXI muestran la consideración que los hablantes tienen de la variedad propia como modelo de español. Si bien los del centro-norte de España, cuyo dialecto es el castellano, son quienes consideran de manera prácticamente unánime a Castilla como la mejor variedad del español, los hablantes andaluces y los canarios se sitúan en el otro extremo, "conscientes de que sus propias variedades históricamente han carecido de reconocimiento y prestigio abierto" (Cestero y Paredes 2018: 34-35). Para los resultados de Sevilla y Granada concretamente, véase Santana (2018) y Manjón Paredes (2018) respectivamente.

${ }^{4}$ Es precisamente en este contexto, las relaciones comerciales con América en la Sevilla de finales del siglo XVI, donde situamos la serie de ficción La Peste, objeto de estudio de este trabajo.

${ }^{5}$ Es en el siglo XIX cuando se consagra la transformación de los viejos tópicos sobre lo andaluz en estereotipos, de manera que se "convierte la valentía en matonismo, la hipérbole en exageración falseadora" y se va consolidando la percepción del andaluz como un tipo humano popular en el que convergen todos los males de la Patria" (Cano 2009, 125).

${ }^{6}$ Según el informe del Ministerio de Educación, Cultura y Deporte sobre el curso 2016-2017,
} 
Todo ello ha generado una valoración negativa de lo andaluz en general y del habla andaluza en particular. En la actualidad, los medios de comunicación contribuyen enormemente a la difusión de una imagen desfigurada de lo que representa la identidad cultural y lingüistica de Andalucía. De este modo, cuando en los informativos se ofrece 'la voz de la calle', esto es, cuando se busca la opinión de la ciudadanía sobre un tema, no falta la intervención de un andaluz de nivel popular que se expresa mal. Se perpetúa así un estereotipo que muestra a los andaluces como ignorantes y se le atribuye a Andalucía un papel secundario en el contexto de España.

Asimismo, los profesionales andaluces de la comunicación, cuando se ponen frente al micrófono, tienden a adoptar una pronunciación claramente dentro del modelo de referencia "estandarizado septentrional", en el que no tienen cabida los rasgos típicos andaluces, sino los propios de la variedad "estándar del español centropeninsular o norteño" (Carbonero, 2007: 126) ${ }^{7}$, pues como ya apuntaron López Morales (1989) o Moreno Fernández (2005), entre otros, las creencias de los hablantes suelen influir en su actitud ante determinados usos lingüísticos, a los que estigmatizan o conceden estatus, al igual que "a las variedades de una lengua o a lenguas en contacto" (Cestero y Paredes 2018: 13).

Sin embargo, "la televisión pública andaluza debe ser para los andaluces un referente de los valores de este pueblo" y debe fomentarlos a través de los contenidos de sus programas, la manera de comunicarlos y la forma de hablar de los presentadores para "reafirmar la conciencia de los andaluces de pertenencia a un pueblo" (Álvarez 2002: 13).

Por otro lado, en los programas de telerrealidad o reality shows (tan de moda en la televisión actual) es frecuente la presencia de andaluces que responden a un perfil determinado: estereotipado. Cabe plantearse si "resulta beneficioso para la construcción social y simbólica del andaluz en el imaginario colectivo" (Teruel y Fernández: 2005).

Cuando se trata de crear secuencias humorísticas o de caracterizar a ciertos personajes en un texto audiovisual de ficción, las variedades dialectales se revelan como uno de los recursos más empleados por los guionistas (Arampatzis: 2013). En el marco del español peninsular, a menudo se opta por el andaluz, el cual se refleja como una modalidad poca prestigiosa, incluso vulgar, que se pone de manifiesto en personajes secundarios, de estrato sociocultural bajo y que, a menudo, aportan el tono de comicidad a la

\footnotetext{
Andalucía es una de las comunidades donde más se acusa el abandono escolar temprano. Disponible en https://www.mecd.gob.es/servicios-al-ciudadano.../Datosycifras 1516esp.pdf (Fecha de consulta, 21 de febrero de 2018).

${ }_{7}^{7}$ Véase el estudio de Díaz Salgado (2002), en el que analiza e interpreta las actitudes de 31 informantes (todos ellos presentadores o redactores de Canal Sur Televisión) ante el uso de determinadas realizaciones fónicas en su ámbito de trabajo.
} 
obra $^{8}$. Se ponen de manifiesto dos de los mitos más frecuentes sobre el andaluz: el de la vulgaridad y el de la gracia, con los que implícitamente tiende a identificarse a los andaluces.

La existencia de este tipo de personajes incultos y graciosos también "perjudicaria la imagen colectiva de los andaluces, que solo serían percibidos a través del estereotipo. Esto es, sin matices y sin estratificación lingüística dentro de ese contexto social" (Méndez, 2009: 260).

Ejemplo de ello son los paralelismos que Rafael Jiménez (2002: 192) establece entre las series Farmacia de guardia, Juntas, pero no revueltas y Médico de familia. En las tres aparecen personajes andaluces que desempeñan trabajos de poco reconocimiento socio-económico y muestran "un uso estereotipado y exagerado, que raya la chabacaneria, de un andaluz que posee rasgos coloquiales y vulgares".

Asimismo, en Médico de familia, el papel de La Juani, la empleada del hogar, lo interpretaba la actriz $\mathrm{M}^{\mathrm{a}}$ Luisa Martín, que no es andaluza, pero exageraba los rasgos de pronunciación de esta modalidad para adecuarse a las características del personaje. Sin embargo, emplear las formas andaluzas por parte de personas ajenas a la comunidad "siempre se ha sentido como un agravio" en el contexto social andaluz, ya que toda imitación propende a la "exageración y a la caricatura" (Méndez 2009: 246).

Son numerosas las series de ficción españolas que reflejan el habla andaluza en personajes graciosos con profesiones poco prestigiosas, pocas luces y escasa cultura (Manuela en Ana y los siete, Emilio en Aqui no hay quien viva, la Chusa en La que se avecina, etc. ), que "se expresan en un andaluz populachero, chocante y barriobajero, estableciéndose con ello una equiparación entre hablar andaluz, ser un gracioso y un cateto ignorante" (Méndez 2009: 260) Estos estereotipos transmiten una imagen falseada de la sociedad andaluza. De ahí el interés que nos ha suscitado la serie La Peste, pues la mayoria de los personajes, independientemente de su clase social y nivel cultural, emplean el modelo fonético andaluz y rompen con estos tópicos.

El objetivo de este trabajo es, por un lado, revisar desde una perspectiva sociolingüística el modelo andaluz que se refleja en esta serie de ficción $y$, por otro, analizar la repercusión mediática que tuvo su estreno en relación con esta cuestión. Con ello, se pretende estudiar el andaluz desde dos perspectivas diferentes: 1 . como conjunto de una serie de rasgos fonéticos que se manifiestan en hablantes andaluces de acuerdo a sus características socioculturales y a las situaciones comunicativas en que se encuentren, y 2 . como objeto de valoraciones explícitas (esto es, análisis de este modo de hablar como un hecho cultural que genera opiniones de diverso tipo).

\footnotetext{
${ }^{8}$ El mito del gracioso andaluz, tan manido en televisión, ya aparecía en el teatro del Siglo de Oro; ya entonces el papel del gracioso estaba "encasillado en un tipo andaluz estereotipado con un bagaje cultural escaso" (Ureña 2014: 176).
} 


\section{CORPUS Y METODOLOGÍA}

Para el estudio de caso de La Peste, se ha tomado como muestra el habla de los once personajes con mayor presencia en la trama en los seis episodios que componen la primera temporada de la serie ${ }^{9}$.

Los criterios de análisis son los siguientes:

a) Sociales: nivel de instrucción de los personajes, profesión o tareas que desempeñan, grupo social al que pertenecen y figura que representan socialmente.

b) Lingüísticos: empleo del modelo de pronunciación norteño o andaluz; en el caso de los personajes andaluces, atención a la presencia/ ausencia de los principales rasgos fonéticos de la modalidad lingüística andaluza ${ }^{10}$ (Bravo y Ropero 2002; Carbonero (2003); Narbona (2003), etc.):

- Seseo, ceceo o distinción $/ s /-/ \theta /$

- Aspiración o pérdida de la /-s/

- Aspiración o pérdida de otras consonantes en posición implosiva

- Aspiración de la / $x /(j, g e, g i)$

- Fenómenos relacionados con las liquidas $/ r /$ y $/ l /$ : neutralización de $/ r /-/ l /$ preconsonántica a favor de $/ r /$ y asimilación del grupo consonántico $[r l]>[l \cdot l]$

- Pérdida de la /-d-/ intervocálica

- Reducciones ${ }^{11}$

- Pronunciación fricativa del fonema / $\mathrm{c} /($ ch): [̌̃ $]$

- Yeísmo

Para analizar su repercusión mediática, se ha rastreado, por un lado, en Google (a partir del filtro "la peste andaluz"12) las informaciones publicadas desde su estreno, el 12 de enero del 2018, en los periódicos digitales y, por

\footnotetext{
${ }^{9}$ Debe tenerse en cuenta que, a pesar de que la serie esté ambientada a finales del siglo XVI, se trata de un guion adaptado al habla actual y, por tanto, hemos estudiado los rasgos fonéticos más relevantes del andaluz en sincronía, y no desde una perspectiva histórica, de acuerdo con los objetivos propuestos.

${ }^{10}$ Aunque ninguno de ellos es extensivo a todo el territorio andaluz ni exclusivo de este (muchos son compartidos por otras hablas peninsulares y/o de América), en su conjunto dotan a la modalidad lingüistica andaluza de un perfil fonético propio.

11 "Bajo esta etiqueta tendremos en cuenta los casos de pérdidas de sonidos, normalmente después de sílaba acentuada, en casos como [...] la preposición "para" [pára / pá] y el adverbio "muy" [mwí / mú]" (Cutillas Espinosa 2003: 6).

${ }^{12}$ Se han tomado solo noticias, no artículos de opinión, ya que lo que pretendemos recoger es cómo los medios de comunicación, en general, informan a la sociedad de cuál es el problema y cuál es su visión al respecto.
} 
otro, se ha establecido una búsqueda en Twitter (también desde ese momento hasta el 31 de enero del mismo año ${ }^{13}$ ) para conocer cuál es la percepción de los espectadores sobre la presencia de la fonética andaluza en la serie. Así, introdujimos la etiqueta "\#LaPeste andaluz" y registramos 202 tuits al respecto que han conformado nuestro corpus final de análisis.

\section{ESTUDIO Y RESULTADOS DEL EMPLEO DEL MODELO ANDALUZ EN LA SERIE}

La Peste es una serie de ficción creada por los sevillanos Alberto Rodríguez y Rafael Cobos, quienes están a cargo de la dirección y el guion respectivamente. Se ha grabado en diversas localizaciones de la capital andaluza y cuenta la historia de unos crimenes cometidos a finales del siglo XVI en Sevilla, cuando la población intentaba sobrevivir a una epidemia de peste. Se muestra así una realidad polarizada: por un lado las luces del Renacimiento y, por otro, las sombras de la miseria y la enfermedad.

Para el estudio del modelo fonético andaluz en la serie hemos seleccionado los once personajes de mayor presencia: cinco de ellos tienen una mayor relevancia en la trama (Mateo Núñez; Celso de Guevara; Valerio Huertas; Luis de Zúñiga; Teresa, viuda de Larrea) y los seis restantes son personajes secundarios (Eugenia; Leandra; Arquímedes; el administrador; Pedro Lanzas; Monardes).

Podemos sintetizar el perfil social de cada personaje en la Tabla 1:

\begin{tabular}{|c|c|c|c|c|}
\hline Nombre y papel & $\begin{array}{c}\text { Grupo so- } \\
\text { cial14 }\end{array}$ & $\begin{array}{c}\text { Nivel de ins- } \\
\text { trucción }\end{array}$ & Ocupación & Representa \\
\hline $\begin{array}{c}\text { Mateo Núñez: prin- } \\
\text { cipal (protagonista) }\end{array}$ & Artesano & Alto & $\begin{array}{c}\text { Dueño de una } \\
\text { imprenta; des- } \\
\text { pués investiga- } \\
\text { dor }\end{array}$ & $\begin{array}{c}\text { El contrapunto } \\
\text { de la religión }\end{array}$ \\
\hline $\begin{array}{c}\text { Celso de Guevara: } \\
\text { principal }\end{array}$ & $\begin{array}{c}\text { Clase privile- } \\
\text { giada (clero) }\end{array}$ & Alto & Inquisidor & La Iglesia \\
\hline $\begin{array}{c}\text { Valerio Huertas: } \\
\text { principal }\end{array}$ & Bajos fondos & Bajo & $\begin{array}{c}\text { Niño de la calle; } \\
\text { después ayu- } \\
\text { dante de Mateo }\end{array}$ & Pícaro \\
\hline $\begin{array}{c}\text { Luis de Zúñiga: } \\
\text { principal }\end{array}$ & Burguesía & Alto & Comerciante & $\begin{array}{c}\text { Auge de los } \\
\text { mercaderes }\end{array}$ \\
\hline
\end{tabular}

\footnotetext{
${ }^{13}$ Aunque se trata de un período breve de tiempo, lo cierto es que, marcados por la actualidad, fueron los días en que se publicó sobre el tema de manera intensa (posteriormente dejó de generar interés y las publicaciones fueron esporádicas); así pues, a partir de febrero las alusiones a La Peste fueron casi todas en relación con Fariñas, la serie que entonces tomó mayor protagonismo en la red social.

14 Como no se trata de llevar a cabo un análisis en profundidad de las clases sociales de la época, sino estudiar el asunto desde un prisma lo más actual posible, hemos tratado de simplificarlo, contemplando las siguientes diferencias sociales: clases privilegiadas (nobleza y clero) y no privilegiadas compuesta por tres grupos: 1. comerciantes, funcionarios y profesionales, comerciantes, artesanos (que podríamos llamar la burguesía), 2. artesanos y trabajadores no especializados y 3. campesinos. Hemos de añadir en los estamentos más bajos los bajos fondos (pícaros y mendigos) y las prostitutas.
} 


\begin{tabular}{|c|c|c|c|c|}
\hline $\begin{array}{c}\text { Teresa, viuda de } \\
\text { Larrea: principal }\end{array}$ & $\begin{array}{c}\text { Clase privile- } \\
\text { giada (no- } \\
\text { bleza) }\end{array}$ & Alto & Pintora & $\begin{array}{c}\text { La mujer rebe- } \\
\text { lada }\end{array}$ \\
\hline $\begin{array}{c}\text { Eugenia: secunda- } \\
\text { rio }\end{array}$ & Bajos fondos & Bajo & $\begin{array}{c}\text { La superviven- } \\
\text { cia de la mujer } \\
\text { de clase popu- } \\
\text { lar }\end{array}$ \\
\hline $\begin{array}{c}\text { Leandra: secunda- } \\
\text { rio }\end{array}$ & $\begin{array}{c}\text { Clase popular } \\
\text { trabajadora } \\
\text { no especiali- } \\
\text { zada) }\end{array}$ & Bajo & $\begin{array}{c}\text { Lava la ropa de } \\
\text { los muertos }\end{array}$ & $\begin{array}{c}\text { Cómo vive la } \\
\text { clase popular la } \\
\text { enfermedad }\end{array}$ \\
\hline $\begin{array}{c}\text { Arquimedes: se- } \\
\text { cundario }\end{array}$ & Bajos fondos & Bajo & Maleante & $\begin{array}{c}\text { La vida al mar- } \\
\text { gen de la ley }\end{array}$ \\
\hline $\begin{array}{c}\text { El administrador: } \\
\text { secundario }\end{array}$ & Burguesia & Alto & Administrador & El servilismo \\
\hline $\begin{array}{c}\text { Pedro Lanzas: se- } \\
\text { cundario }\end{array}$ & Artesano & Medio-alto & Impresor & $\begin{array}{c}\text { La clandestini- } \\
\text { dad }\end{array}$ \\
\hline $\begin{array}{c}\text { Monardes: secun- } \\
\text { dario }\end{array}$ & Profesional & Alto & Médico & La Ciencia \\
\hline
\end{tabular}

Tabla 1: Perfil social de los personajes

El nivel de instrucción es directamente proporcional al nivel social, de manera que es más alto cuando mayores son las posibilidades económicas y la posición social. Así, poseen un nivel de instrucción bajo los cuatro personajes de clase baja y alto los siete restantes.

En cuanto al habla de los personajes, es interesante tener en cuenta el modelo de pronunciación que emplea cada uno, ya que tres de ellos poseen una fonética norteña, alejada de los hábitos meridionales. Son los tres personajes con mayor nivel instruccional y gusto por las artes y la cultura, junto al inquisidor, que sí habla en andaluz. Nos referimos al protagonista, Mateo Núñez, al médico Monardes y a la pintora, viuda de Larrea.

La Sevilla de la época resultaba un polo de atracción para gente de muy diverso estrato social y cultural, por lo que no es extraño que aparezcan personajes que, aunque procedan de cualquier otro lugar de la Península y, por tanto, tengan un modelo de pronunciación distinto, se encuentren afincados en la ciudad hispalense. Sin embargo, resulta llamativa la elección del modelo fonético diferente en estos tres personajes concretos: en el caso de Mateo, mantiene la tónica general de las series españolas, donde lo andaluz no suele estar presente en los papeles protagonistas. En el caso de Monardes, está inspirado en un sevillano ${ }^{15}$, pero en la serie se prefiere para su caracterización un modelo de pronunciación norteño y en cuanto a Teresa es la única representante de la nobleza, uno de los dos grupos sociales privilegiados.

Así pues, descartados para este criterio estos personajes de pronunciación norteña, hemos centrado nuestra atención en el habla de los ocho personajes andaluces. Insistimos en que lo más llamativo de hablar andaluz es

\footnotetext{
${ }^{15}$ En la céntrica calle Sierpes de Sevilla se conserva un azulejo en el que puede leerse: "En este lugar estuvo situado el jardín botánico medicinal de Nicolás Monardes Alfaro (1493-1588), sevillano universal e introductor de la materia médica americana en Europa”.
} 
la fonética, pese a las evidentes diferencias que existen entre unos andaluces y otros. "No coincide la extensión y el alcance vertical o sociocultural de unos rasgos y otros. Y no todos los que se consideran característicos tienen, ni mucho menos, igual aceptación y prestigio, no solo fuera, sino también dentro de la región" (Narbona 2003: 22).

A pesar de toda esta divergencia, pueden distinguirse objetos relativamente homogéneos dentro de la comunidad desde los puntos de vista diatópico y diastrático. Así pues, hemos puesto el foco en una serie de rasgos comunes y extendidos entre los hablantes de, al menos, Andalucia occidental (en particular en Sevilla):

a) seseo, ceceo o distinción /s/-/ $\theta /$ : Para Carbonero (2003: 116) es este "probablemente el punto de mayor conflicto sociolingüistico en el andaluz actual", dado los complejos factores que en él intervienen y la dispersión de los resultados fonéticos producida entre las tres soluciones.

El seseo meridional español, presente en Canarias y en parte de Andalucía, así como el hispanoamericano gozan de total aceptación en la norma culta. Sin embargo, en la serie solo aparece esporádicamente en el habla de algún personaje secundario (ninguno de los aquí analizados). Quizás se deba a un intento de distanciarse de la tendencia en las series españolas a que los personajes andaluces aparezcan con un seseo exagerado.

La mayoria de los personajes analizados, siete de los ocho, independientemente de su estrato social, propenden a la distinción, reflejando así lo que en la actualidad es una preferencia al alza en diversas áreas urbanas andaluzas.

Así pues, en Córdoba, Granada, Huelva, Jerez de la Frontera o Málaga se advierten patrones comunes: las soluciones vernáculas (seseantes o ceceantes dependiendo de la zona) han ido dando paso paulatinamente a la pauta de distinción. Aunque cuentan con matices diferenciadores, se aprecian también elementos en común en relación con la distribución diastrática de dicha variación: el proceso de convergencia hacia el modelo septentrional "está liderado por los sujetos con mayor formación académica y a menudo está respaldado también por los jóvenes y por las mujeres" (Santana: en evaluación). Se debe, entre otros motivos, a la "posible influencia de los medios de comunicación de alcance suprarregional y las fáciles corrientes de intercambio social y cultural entre hablantes de diferentes zonas de la Península" (Carbonero 2003: 117).

En cuanto al ceceo, se trata de la solución tradicional entre las clases populares y goza de escaso prestigio, especialmente en las áreas urbanas ${ }^{16}$.

\footnotetext{
16“'Se extiende por toda la costa gaditana, prolonga su dominio hacia el interior de la provincia de Sevilla, donde ocupa más de la mitad sur, toda la provincia de Cádiz, algunas localidades del sur de Córdoba, más de la mitad sur de Málaga, el oeste de Granada y, en algunos casos, el sudeste de Almería” (RAE y ASALE 2001: 190-191).
} 
Solo un personaje en la serie, Arquimedes (el viejo de los bajos fondos y maestro de la delincuencia para los huérfanos que recoge), tiene una pronunciación ceceante. Seguramente por sus características negativas se le ha asignado este rasgo de pronunciación. Ya los hermanos Álvarez Quintero establecian diferencias entre los personajes según su forma de pronunciar: en todos sus sainetes y comedias principales "siempre sesea el personaje fino, urbano y/o simpático; el ceceo es rural, o está matizado peyorativamente" (Marcos Marín 1990: 55):

(1) Tenga cuidado con é $\theta e^{17}$, es crianza del demonio (Arquímedes. Ep.1 40:12).

Además, este ceceo unido a otras particularidades de Arquímedes, nos lleva a identificarlo con el estereotipo gitano que desde mediados del siglo XVI se vincula al origen cultural y lingüístico de lo andaluz ${ }^{18}$.

b) Aspiración o pérdida de la /-s/: se trata de un fenómeno generalizado en el español meridional tanto en posición final de sílaba como de palabra y lo encontramos en los ocho personajes andaluces analizados:

(2) Le ruego que sea lo máh dihkréto posible (El Inquisidor. Ep.2 12:13)

(3) No ehtá en la mancebía. Intentó trabajar por su cuenta y Moreno la ha expulsado (El administrador. Ep.3 11:01)

Sin embargo, encontramos una diferencia en posición final de palabra según el grupo sociocultural, de modo que en muchas ocasiones los de clase más alta mantienen la /-s/ y por el contrario los de grupos inferiores la pierden:

(4) ¿Y usted? ¿No va a hacer nada má? (Eugenia. Ep.6 15:09)

(5) ¿No kiéreh más? (Zúñiga. Ep.1 14:52)

En cuanto al fenómeno comúnmente denominado heheo (la aspiración de la /-s-/ intervocálica en posición interior de palabra), tiene una baja consideración y es un rasgo ausente en todos los personajes analizados, incluso en los del nivel sociocultural más bajo.

c) Aspiración o pérdida de otras consonantes en posición implosiva:

En términos generales, la posición implosiva, que implica un debilitamiento consonántico, "está bastante generalizada en el mundo hispánico y en Andalucía adquiere relevancia especial, sobre todo en contraste con las

\footnotetext{
${ }^{17}$ Solo hemos transcrito la pronunciación del elemento que interesa en cada caso, destacado en cursiva.

${ }^{18}$ En El Criticón de Baltasar Gracián (1651) aparece una mención al ceceo que alude conjuntamente a gitanos y andaluces (Morillo-Velarde 2009: 180).
} 
áreas más septentrionales de la Península" (Carbonero 2003: 113). Es un fenómeno generalizado en los ocho personajes, especialmente con respecto a las consonantes / $-d /, /-r /, /-l /$ implosivas en final de palabra, aunque con resultados diferentes: algunos personajes las aspiran y en otros desaparecen, si bien en el caso concreto de la /-d/ suele perderse en el habla de todos ellos:

(7) No es kasualidá que nos hayamos encontrado así de repente. Uhté está aquí por una razón mayor, de la que todo somos siervos (El Inquisidor. Ep.2 6:40)

(8) Yo sí. No me da miedo la enfermedá (Valerio. Ep.2 33:41)

(9) Señora, es la autoridá. Es mejor hacerlo por las buenas (El administrador. Ep.5 27:24)

Las liquidas son aspiradas (e incluso el Inquisidor tiende a mantener el sonido sin aspirar):

(10) Pruébalo. Se llama chocolate. Aunque tenga ese colóh, es una delicia (Zúñiga. Ep.1 40:39) (11) ¿Sabías que un hombre le cortó las manos a su hijo para que mendigara? Sé que está prohibido, que si te cogen te meten en la kárӨeh (Leandra. Ep.2 41:32)

Sin embargo, en el caso de Arquímedes, Eugenia y Pedro Lanzas lo que se observa es la elisión:

(12) Tú y tu sentido del onó. Algún día dejarás de pensá como un militá (Pedro Lanzas. Ep.3 $37: 48)$

(13) ¿Uhté lo va a pagá? (Eugenia. Ep.3 12:51)

d) Aspiración de la $/ x /(j, g e, g i)$ frente a la pronunciación fuerte castellana de la velar fricativa sorda: es un fenómeno que, aunque "variable respecto al punto de articulación y a la intensidad de su fricación", está generalizado en todos los niveles sociales (Carbonero 2003: 113). Así pues, está presente en todos los personajes de la serie, sin que ninguno llegue a la pérdida total de esta aspiración meridional, pues en ese caso gozaría ya de escaso prestigio (Carbonero 2003: 115).

Efectivamente, existen variantes de pronunciación que pueden coexistir en el interior de cada zona y su aparición está determinada básicamente por la situación de habla. Las tres soluciones son: aspiración faríngea sorda (la más frecuente en el andaluz occidental), aspiración faringea sonora y "un sonido intermedio entre la aspiración y la fricación velar (pronunciación castellana)" (Narbona 2003: 203).

Así pues, distinguimos la pronunciación del Inquisidor, el personaje andaluz de mayor nivel social y cultural, pues emplea un registro más cuidado en el que la aspiración es más suave que en el resto de personajes:

(14) Este es su sambenito. Mandé que me lo trahéran cuando me dihéron que había vuelto. (El Inquisidor. Ep.2 4:43) 
e) Fenómenos relacionados con las líquidas $/ r / \mathrm{y} / l /:$ neutralización de $/ r /-/ l /$ preconsonántica a favor de $/ r /$ y asimilación del grupo consonántico $[r l]>[l \cdot l]$.

En cuanto al primero, vemos ejemplos solo en el personaje de Arquímedes:

(15) Tenga cuidado con ese, es crianza der demonio (Arquímedes. Ep.1 40:12)

(16) Con la ciudad cerrada hay demasiados Oordáoh (Arquímedes. Ep.3 18:04)

Sobre la asimilación, con frecuencia se produce por el encuentro entre la $-r$ final de los infinitivos ante un pronombre enclítico de tercera persona. En ese contexto fonético, "por razones de asimilación anticipatoria", es mayoritaria en Andalucía la solución - $l$, produciéndose así una geminación (Narbona 2003: 193).

Es un fenómeno presente en los personajes de nivel popular, salvo en Valerio, que ni siquiera aspira la / $r /$. Quizás se deba a que el actor no es andaluz y solo imita algunos rasgos:

(17) Está prohibido vender la ropa de los muertos. Hay que kemállla (Leandra. Ep.1 32:49)

(18) Yo también puedo matálle a él. No tengo que pagállle a nadie por lo que hago (Eugenia. Ep.3 13:09)

(19) Puedo buhkállle otro mejor (Arquímedes. Ep.1 26:51)

De los otros cuatro personajes restantes, tenemos ejemplos de tres (no así de Pedro Lanzas): en dos sí se produce una aspiración de la $/ r /$, pero de nuevo el Inquisidor muestra un habla más cuidada:

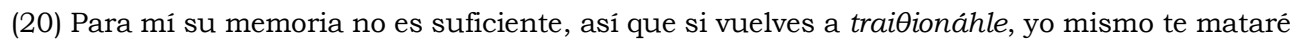
(Zúñiga. Ep.2 15:50)

(21) Esa mujer es una rebelde, señora Larrea. No le conviene. Puedo buskáhle otra (El Administrador. Ep.3 11:13)

f) Pérdida de la /- $d$-/ intervocálica: hemos encontrado casos diversos, pues en España, "la elisión de /d/ es un fenómeno de variación muy complejo en el que tiene gran importancia la frecuencia léxica" (RAE y ASALE 2011: 146).

Con respecto a los participios, hemos de establecer una diferencia en la aceptación social de este fenómeno según la terminación. Si bien la pérdida de la /- $d-/$ intervocálica en los terminados en -ado es un fenómeno generalmente extendido en todo el mundo hispánico y, por tanto, tiene prestigio social, cuando terminan en -ido parece que disminuye la extensión y "no gozan de aceptación social en ámbitos cultos" (Bravo y Ropero 2002: 189).

De los cuatro personajes de clase baja, hemos encontrado usos de participios terminados en -ado en Valerio, Eugenia y Leandra, pero solo la última elimina la $-d-$ : 
De los cuatro personajes de nivel sociocultural más alto, hemos encontrado muestras en otros tres: el Inquisidor, el Administrador y Zúñiga. En los ejemplos de los dos primeros, no se pierde nunca, pero en el caso de Zúñiga tenemos ejemplos en los que la / $d-d$ se pierde, quizás porque se trata de un registro familiar (habla con su amigo Mateo):

(23) ¿Por qué no has entráo por la puerta? (Zúñiga. Ep.1 14:22)

La /-d-/ de los participios de la segunda y tercera conjugación se pierde también de manera constante, además de en las hablas rurales de toda Andalucia, "en el habla familiar y descuidada de las hablas urbanas. No obstante, la elevación del nivel de conciencia del propio discurso por alteración de la situación comunicativa produce un grado mayor de retenciones que el de los participios de la primera" (Narbona 2003: 215).

Para el participio -ido, no hemos encontrado muestras de su pérdida en ningún personaje. No obstante, la desaparición de la /- $d-/$ en adjetivos, sustantivos, asi como en otros elementos gramaticales tiene menor aceptación y de ello sí tenemos ejemplos en dos personajes:

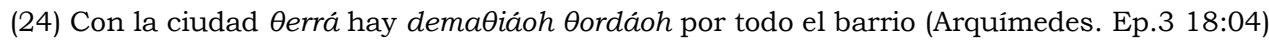

(25) Fueron dos meses de tortura. Demasiáo (Pedro Lanzas. Ep.3 39:53)

Asimismo, en un estudio de Jiménez (2015: 206) sobre el mantenimiento y la pérdida de la /-d-/ intervocálica en el nivel popular del habla de Sevilla señala que todo y nada son dos de las unidades léxicas donde más se elide. Es habitual en el habla de Arquímedes:

(26) En esta ciudad na es gratis, ni morirse es gratis (Arquímedes. Ep.1 26:55)

(27) Quítatelo to, que vea bien lo que compra (Arquímedes. Ep.1 30:56)

Sin embargo, no está presente en el resto de personajes de clases sociales bajas de la serie, salvo en el caso de Eugenia, a la que se lo escuchamos una única vez:

(28) Es hermoso, el más hermoso de toh (Eugenia. Ep.6 15:30)

g) En relación con los ejemplos 26-28, otras reducciones tales como $m u$ (muy) o pa (para) también poseen "una escasa valoración en los niveles cultos, aunque la mayor parte de ellos tiene una amplia extensión social popularmente generalizada en el lenguaje coloquial (Carbonero 2003: 115). Los únicos personajes que lo emplean son Leandra, Arquímedes y Zúñiga, aunque en el caso de este último solo se lo es escuchamos esporádicamente cuando se dirige a su amigo Mateo en una situación de intimidad: 
(29) ¿Sabías que un hombre le cortó las manos a su hijo pa que mendigara? (Leandra. Ep.2 41:32)

(30) Pastilla de fuego sagrado. Pa ahuyentar la peste (Arquímedes. Ep.3 18:18)

(31) Coge uno. Son pa los dientes (Zúñiga. Ep.1 15:37)

h) Pronunciación fricativa de $(c h)$ : $[\hat{c}]>[\check{s}]$. Se trata de un rasgo de "distribución eminentemente meridional y, en su mayoria, ceñida a las costas andaluzas, tradicional vivero de la imagen estereotipada del andaluz, que, sin duda por ello", suele incorporarlo con cierta frecuencia, a pesar de su relativa rareza en el resto de Andalucía (Narbona 2003: 178). En términos generales, "se puede decir, salvo excepciones, que predomina una escasa aceptación de este fenómeno en Andalucía" (Carbonero 2003: 116).

Por todo ello, nos parece que el deseo de distanciarse del modelo fonético de andaluz estereotipado de las series españolas de televisión puede explicar la ausencia de este rasgo en el habla de todos los personajes, incluso en los de nivel sociocultural bajo.

i) Yeísmo: consiste en la confusión entre la consonante palatal central fricativa sonora ( $y$ con valor consonántico) y la palatal lateral (ll) en favor de la primera. Más allá de un fenómeno meridional, se trata en realidad de un "cambio generalizado en casi todo el español hablado, sobre todo en las ciudades, de modo que los restos de la distinción se confinan en ámbitos rurales aislados, algunos en el español andaluz" (Morillo-Velarde 2009: 139-140) ${ }^{19}$. Así pues, su presencia en amplias zonas de España y América, así como su creciente expansión, hacen de este fenómeno un uso aceptado en la norma culta (RAE y ASALE 2005).

Se trata de un rasgo común a todos los personajes; quizás una pronunciación diferenciada hubiera resultado dificil de realizar para el actor o actriz y extraña para los espectadores.

Veamos los resultados expuestos gráficamente:

\footnotetext{
${ }^{19}$ Quedan puntos distinguidores especialmente en el andaluz oriental, aunque también se han detectado casos en las cercanías de Sevilla, en el área serrana y en algunos puntos de la costa de Huelva. La distinción, en cualquier caso, está asociada a ciertos entornos rurales y a personas de edad mediana o avanzada" (RAE y ASALE 2011: 223). Algunos pueblos en los que aún pueden rastrearse huellas de la distinción son Bollullos del Condado, Lepe o Paymogo (Bravo y Ropero 2002: 189).
} 


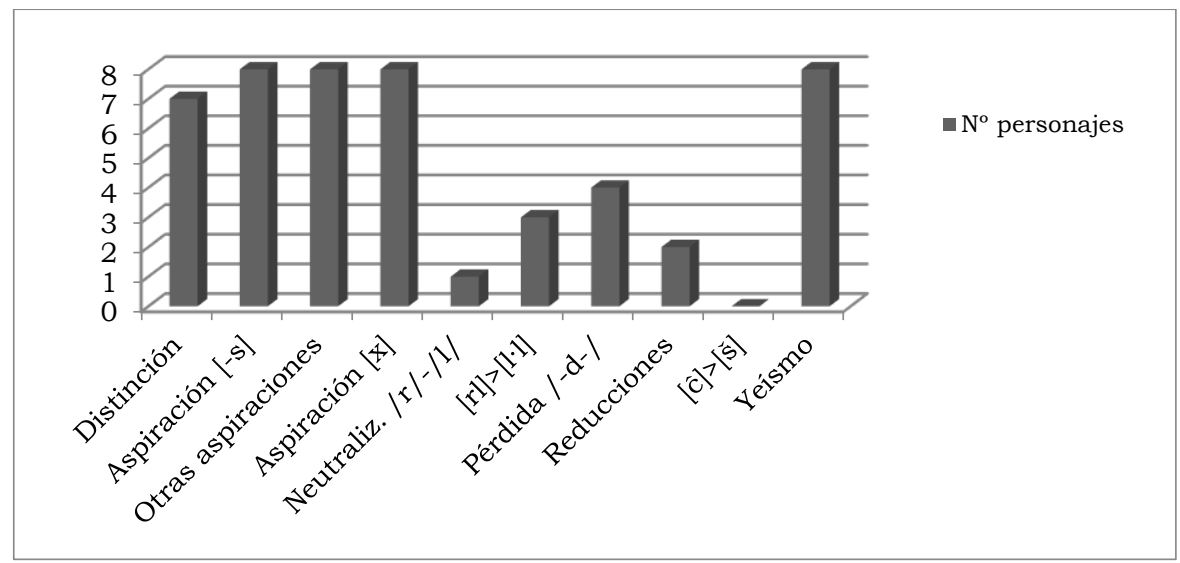

Gráfico 1: Aparición de rasgos analizados en los personajes andaluces

Como puede observarse en el Gráfico 1, la mayoria de los rasgos presentes en el habla de los personajes analizados, independientemente de su clase social o su nivel de instrucción, son aquellos que gozan, por un lado, de una enorme extensión en el español meridional (las aspiraciones de $-s$ y $[x]$ ) e incluso en otros ámbitos del mundo hispánico (la distinción o el yeísmo) y, por otro, de es una valoración alta desde un punto de vista sociolingüístico.

Aun así, observamos comportamientos distintos en dos personajes. Por un lado, en Arquímedes: solo en su caso (no solo por ser el personaje de los bajos fondos, sino también por su bajeza personal) aparecen rasgos de poco prestigio social, tales como el ceceo, la neutralización $r / l$ a favor de $r$ o las reducciones. Pero ni siquiera en este está presente la pronunciación fricativa de $c h$, tan frecuente en los personajes andaluces del resto de series de televisión. Por otro, el caso del Inquisidor, que, con su habla cuidada, intenta acercarse a una forma de hablar ideal que situamos próxima al modelo norteño que ofrecen, en general, los medios de comunicación.

\section{ESTUdIO Y RESULTADOS DEL ANÁLISIS DE LA REPERCUSIÓN MEDIÁTICA}

Desde el estreno de la serie comienzan a publicarse numerosas informaciones sobre la repercusión que ha tenido la elección del acento andaluz de los personajes. Así pues, hemos recogido en la Tabla 2 las entradas en Google de medios de comunicación (a partir de la búsqueda "la peste andaluz") sobre el asunto:

\begin{tabular}{|l|c|c|c|}
\hline \multicolumn{1}{|c|}{ Nombre medio } & Fecha & Titular & Contenido \\
\hline www.elperiodico.com & $24 / 01 / 18$ & $\begin{array}{l}\text { El polémico acento an- } \\
\text { daluz de 'La peste' }\end{array}$ & $\begin{array}{c}\text { Foco en el } \\
\text { acento }\end{array}$ \\
\hline$\underline{\text { www.elconfindencial.es }}$ & $20 / 01 / 18$ & $\begin{array}{l}\text { ¿Por qué molesta que se } \\
\text { hable con acento anda- } \\
\text { luz en 'La Peste'? }\end{array}$ & $\begin{array}{l}\text { Foco en el } \\
\text { acento }\end{array}$ \\
\hline
\end{tabular}




\begin{tabular}{|c|c|c|c|}
\hline www.huffingtonpost.es & $16 / 01 / 18$ & $\begin{array}{l}\text { Críticas y alabanzas por } \\
\text { el acento andaluz en 'La } \\
\text { Peste' }\end{array}$ & $\begin{array}{l}\text { Vocalización } \\
\text { de los actores }\end{array}$ \\
\hline www.diariodeleon.es & $24 / 01 / 18$ & $\begin{array}{l}\text { El polémico acento an- } \\
\text { daluz de 'La Peste' }\end{array}$ & $\begin{array}{l}\text { Foco en el } \\
\text { acento }\end{array}$ \\
\hline www.larazon.es & $20 / 01 / 18$ & $\begin{array}{l}\text { El zasca de Susana Díaz } \\
\text { a los que critican el } \\
\text { acento andaluz de "La } \\
\text { Peste" }\end{array}$ & $\begin{array}{l}\text { Foco en el } \\
\text { acento }\end{array}$ \\
\hline www.vertele.eldiario.es & $20 / 01 / 18$ & $\begin{array}{l}\text { Susana Díaz sale a de- } \\
\text { fender el acento andaluz } \\
\text { de La Peste tras las criti- } \\
\text { cas }\end{array}$ & $\begin{array}{l}\text { Foco en el } \\
\text { acento }\end{array}$ \\
\hline www.diariodealmeria.es & $20 / 01 / 18$ & $\begin{array}{l}\text { Susana Díaz defiende el } \\
\text { acento andaluz en 'La } \\
\text { Peste' }\end{array}$ & $\begin{array}{l}\text { Foco en el } \\
\text { acento }\end{array}$ \\
\hline www.cordobabuenasnoticias.com & $23 / 01 / 18$ & $\begin{array}{l}\text { Famosos salen en defensa } \\
\text { del acento andaluz en "La } \\
\text { Peste" }\end{array}$ & $\begin{array}{l}\text { Foco en el } \\
\text { acento }\end{array}$ \\
\hline www.periodicoextremadura.com & $25 / 01 / 18$ & $\begin{array}{l}\text { El polémico acento an- } \\
\text { daluz de 'La peste' } \\
\text { desata críticas }\end{array}$ & $\begin{array}{l}\text { Foco en el } \\
\text { acento }\end{array}$ \\
\hline www.elnortedecastilla.es & $23 / 01 / 18$ & $\begin{array}{l}\text { Susana Díaz sale en de- } \\
\text { fensa del acento andaluz } \\
\text { de 'La Peste' }\end{array}$ & $\begin{array}{l}\text { Foco en el } \\
\text { acento }\end{array}$ \\
\hline www.elperiodicodearagon.com & $24 / 01 / 18$ & $\begin{array}{l}\text { El polémico acento an- } \\
\text { daluz de 'La peste' }\end{array}$ & $\begin{array}{ll}\begin{array}{l}\text { Foco en el } \\
\text { acento }\end{array} & \\
\end{array}$ \\
\hline www.heraldo.es & $03 / 02 / 18$ & $\begin{array}{l}\text { 'La Peste', una superpro- } \\
\text { ducción española infec- } \\
\text { tada por la polémica }\end{array}$ & $\begin{array}{l}\text { Foco en el } \\
\text { acento }\end{array}$ \\
\hline
\end{tabular}

Tabla 2: Contenido de las noticias publicadas sobre la polémica

Se aprecia en ella que de los trece medios que se hicieron eco de esta polémica, doce de ellos toman el acento andaluz como causa fundamental de las quejas de los espectadores por la falta de entendimiento:

Los usuarios de redes sociales ponían en duda la escasa capacidad de vocalización y la dicción del elenco, pero la mayoría achacaba su escasa comprensión de las escenas o la dificultad para seguir los diálogos al acento de los intérpretes, menos neutro de lo habitual, y reclamaban con más o menos ironía la necesidad de emitir la serie con subtítulos. (El Periódico, 24/01/18)

Tan solo uno prioriza otra causa y explica que la mayoría de los tuiteros, en realidad, "ha asegurado que esto se debe a la vocalización de los actores" (El Huffington Post, 16/01/18).

Por otra parte, en cuanto a las opiniones que los espectadores han publicado en la red social Twitter, hemos registrado 202 tuits con la etiqueta "\#lapeste andaluz" desde su estreno hasta el 31 de enero de 2018 y los hemos distribuido en tres bloques según su temática: a) Alabanzas y defensa 
del modelo andaluz; b) Críticas al sonido o falta de vocalización de los actores; c) Críticas al modelo de pronunciación andaluza. Y estos han sido los resultados:

a) Alabanzas y defensa del modelo andaluz: 145 de los tuits defienden el acento andaluz de la serie, alegando en su mayoría que el tratamiento que se le ha dado es necesario para romper estereotipos, y atacan a quienes solo lo aceptan en personajes graciosos y vulgares:

Carlos Guti@carlosguti198916 ene.

\#LaPeste el problema lo tiene la gente con el andaluz porque les sigue chirriando cuando lo escuchan de personajes que no son graciosos, cantantes de flamenco o toreros.

Marta Bege@martabege 23 ene.

La gente se queja de la serie La Peste porque al ser muchos actores andaluces, no se entiende... ¡Y a mí desde un principio me pareció que casi no había acento andaluz! No entiendo esas quejas, se entiende todo perfectamente (será porque soy canaria o.Ô) \#LaPeste

b) Críticas al sonido o falta de vocalización de los actores: la mayoría de los tuiteros que se quejan de la ininteligibilidad del habla de los personajes descartan en realidad que se deba al acento andaluz y manifiestan sus quejas en torno a problemas técnicos de sonido, a la falta de vocalización de los actores o a ambos factores; 48 de los tuits se enmarcan en esta opinión:

Kate Austen@KateAusten518 ene.

Cuando hablan de que no se entienden los diálogos de \#LaPeste se refieren a que los actores no vocalizan (como la mayoría de los españoles) y a la mala calidad del sonido, algo común en muchísimas de nuestras peliculas. Un andaluz bien hablado y con buen sonido lo entienden todos.

Estela@Interstelafx 21 ene.

El problema de \#LaPeste no es el acento andaluz, es la mala dicción y esa obsesión por susurrar en las series españolas, si a esto le unimos un sonido con mucho eco pues....pese a eso, la serie es muy buena.

c) Críticas al modelo de pronunciación andaluza: tan solo 9 de los tuits encuentran en el acento la razón de esta ininteligibilidad:

Pau@_Pau_C_20 ene.

\#LaPeste, buenísima producción dirigida por@777albertor. Cruda y dura pero muy bien realizada. El pero es que en ocasiones necesitaría subtítulos porque el andaluz del siglo XVI no se entiende, quillo! ; ) \#Nooslaperdais 
Zurda @_FresasconNata 22 ene.

Tío, pues yo siempre veo las series en versión original, los doblajes son una mierda... Pero La peste estoy esperando que la doblen al inglés porque no hay quién entienda el andaluz... JEFE, UN BOCADILLO DE CALAMARES. \#LaPeste

Veámoslo gráficamente:

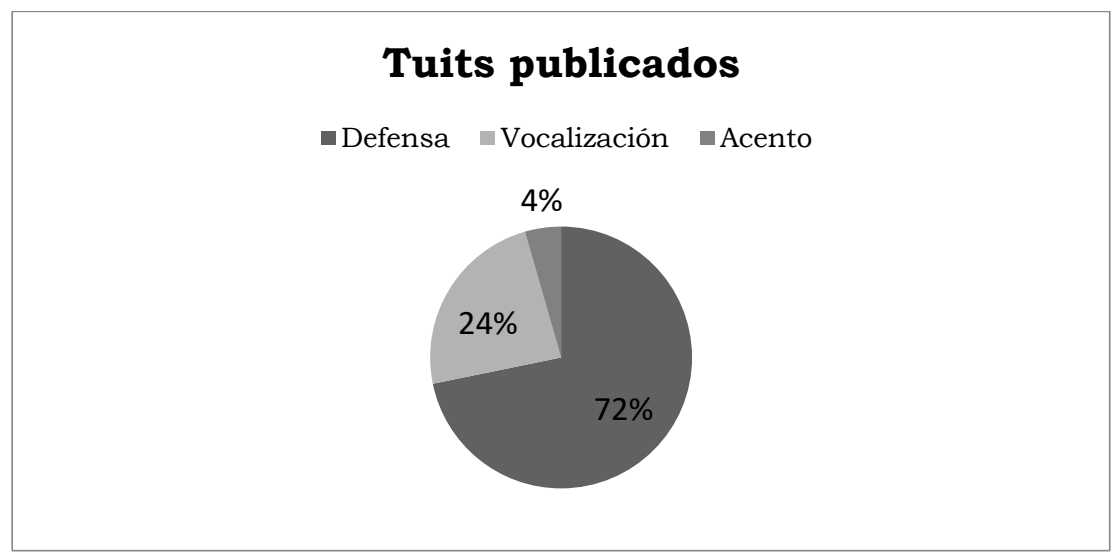

Gráfico 2: Contenido de los tuits publicados sobre la serie

Como se muestra en el Gráfico 2, no existe tal ataque en Twitter, ya que las criticas, minoritarias con respecto a las defensas de la pronunciación andaluza, se centran en realidad en la mala vocalización y el sonido. Si bien es cierto que la ininteligibilidad es otro de los mitos más frecuentes que se ha atribuido tradicionalmente al habla de los andaluces, "la cuestión no se centra en el hecho de pertenecer a una determinada área geográfica, sino más bien en la capacidad de cada individuo para comunicarse y hacerse comprender" (León-Castro, 2016: 1589). No obstante, parece que son los medios de comunicación los que siguen alimentando este mito; con respecto a la serie La Peste, son responsables de haber extendido la creencia de que la sociedad persiste en su rechazo a la variedad andaluza como una alternativa válida para sustituir al modelo norteño, el cual goza casi de exclusividad en determinados formatos y series de televisión. Han fomentado así el malestar de muchos ciudadanos, especialmente de andaluces, que han salido en defensa de esta modalidad lingüistica a través de Twitter.

\section{Conclusiones}

La modalidad lingüística andaluza ha gozado desde su origen de una valoración negativa no solo por su alejamiento del castellano, sino más bien por motivos sociopolíticos, económicos y culturales vinculados al desarrollo de la región. 
Los medios de comunicación, como modelo de autoridad hoy en día y agente socializador, han potenciado ese desprestigio a través de vías diversas: ya sea negando su aparición como registro culto en el habla de los profesionales de la comunicación, ya sea ofreciendo una imagen desfigurada y cargada de mitos de lo andaluz.

En este sentido, las series de televisión, como producto cultural, han contribuido enormemente a extender esa imagen estereotipada a través de personajes andaluces incultos, graciosos y de estrato social bajo, que a menudo se expresan con vulgarismos y rasgos que gozan de escasa aceptación social.

La Peste se aleja de ese comportamiento y presenta una trama de suspense ambientada en Sevilla donde la mayoría de los personajes principales y secundarios, independientemente del perfil social que representen, se expresan con rasgos de pronunciación muy extendidos en la región andaluza (muchos incluso en otros territorios del ámbito hispánico) y socialmente bien valorados. Son rasgos, por tanto, que no obstaculizan la comunicación, aunque pudieran provocar extrañamiento en algún espectador poco habituado a escuchar este modelo fonético.

Desde un punto de vista lingüístico, resulta un acierto, pues invita a reflexionar sobre la necesidad de que los medios de comunicación permitan la aparición de otras variedades lingüísticas, más allá del casi omnipresente modelo norteño.

Ha proyectado una pronunciación basada en rasgos de prestigio presentes en la modalidad andaluza que podría contribuir a perfilar un registro regional estandarizado, a pesar de que para algunos lingüistas no es posible.

Para Narbona (2009: 48), la pretensión de una normalización del andaluz requiere plantear cuestiones que conducen a reflexionar sobre si hay alguien legitimado para imponer ciertos usos hablados a quienes no lo practican o con qué propósitos se llevarian a cabo tales iniciativas. Méndez (2009: 300) también se muestra escéptica con respecto a la idea de planificar una "norma lingüística andaluza", la cual no considera ni necesaria ni exigida por los andaluces.

Sin embargo, debe entenderse como un modelo flexible, de forma que los hablantes cultos puedan "elegir libremente, de acuerdo con aquellos rasgos que definan su identidad social y cultural (Carbonero, 2003: 118). También Villena (1997: 314) apoya la tarea de "discriminar rasgos de un estándar regional".

Vaz de Soto (1995: 77) defiende que lingüisticamente prime la variedad y la tolerancia entre los profesionales andaluces en el ámbito de los medios de comunicación, pero insiste en que no deben estar reñidas "con la tendencia a una pronunciación andaluza más normalizada", ecléctica y no preceptiva.

Finalmente, creemos interesante también el papel que los medios han tenido en la difusión de la recepción del modelo de pronunciación de La Peste por parte de los espectadores. Pese a que son escasísimos los tuits registrados durante el periodo analizado que atacan el acento andaluz de la serie (la mayoría de los que tienen dificultades para entender los diálogos lo 
atribuyen a un problema de sonido técnico o mala vocalización de los actores, independientemente de su procedencia), los medios focalizan dicho acento como la causa principal de esa ininteligibilidad. Por tanto, creemos que son los medios de comunicación los que avivan la polémica en Twitter y generan el malestar entre ciudadanos que han publicado una mayoria de tuits defendiendo la modalidad andaluza. Son responsables de persistir en los tópicos andaluces presentes en el imaginario colectivo y de obstaculizar, por tanto, el cambio en la percepción que se tiene de lo andaluz socialmente.

\section{REFERENCIAS}

ÁLVAREZ SECADES, C. (2002): "Andalucia en Canal 2 Andalucía", de las Heras Borrero, Jerónimo (et al.) (eds.): Modalidad lingüística andaluza. Medios de comunicación y aula. Huelva: J. Carrasco, pp. 11-16.

ARAMPATZIS, C. (2013): "Las variedades no estándar en la comedia de situación estadounidense y su doblaje al español: un estudio descriptivo", Trans, $n^{\circ} 17$. Universidad de Málaga.

BRAVO GARCÍA, E. M. ${ }^{a} \&$ ROPERO NÚÑEZ, M. (2002): "El habla de Andalucía y el español de América. El español hablado en Cuba", Navarro García, J. R. (coord.): Cuba y Andalucía entre las dos orillas. Sevilla: Junta de Andalucía y Consejo Superior de Investigaciones Científicas, pp. 183-213.

CANO AGUILAR, R. (2009): "Lengua e identidad en Andalucia: visión desde la historia", Narbona Jiménez, A. (coord.), La identidad lingüística de Andalucía. Sevilla: Centro de Estudios Andaluces, pp. 67-131.

CARBONERO CANO, P. (2003): Estudios de Sociolingüística Andaluza. Sevilla: Secretariado de Publicaciones de la Universidad de Sevilla.

CARBONERO CANO, P. (2007): "Formas de pronunciación en Andalucía: modelos de referencia y evaluación sociolingüística",
Carbonero Cano, P. (dir.) y Santana Marrero, J. (ed.), Sociolingüística Andaluza, 15. Estudios Dedicados al Profesor Miguel Ropero. Sevilla: Secretariado de Publicaciones de la Universidad de Sevilla, pp. 121-132.

CESTERO, A. M. ${ }^{\mathrm{a}}$ \& PAREDES, F. (2018): "Creencias y actitudes hacia las variedades cultas del español actual: el proyecto PRECAVES XXI" en Boletin de Filologia, tomo LIII, vol.2. Universidad de Chile, pp. 11-43.

CUTILLAS ESPINOSA, J. A. (2003): "Variación estilística en los medios de comunicación: una aproximación contrastiva a la teoría del diseño de la audiencia", Tonos Digital: Revista de estudios filológicos, $\mathrm{n}^{\circ} 5$. Murcia: Servicio de Publicaciones de la Universidad de Murcia.

DÍAZ SALGADO, L. C. (2002): "Creencias y actitudes sobre usos fónicos "innovadores" del andaluz en los periodistas sevillanos de Canal Sur Televisión" en Tonos Digital: Revista de estudios filológicos, $n^{\circ}$ 3. Murcia: Servicio de Publicaciones de la Universidad de Murcia.

JIMÉNEZ FERNÁNDEZ, R. (2002): “El andaluz en los medios de comunicación: la caricatura lingüistica del sur", de las Heras Borrero, Jerónimo et al. (eds.): Modalidad lingüistica andaluza. Medios de comunicación y aula. 
Huelva: J. Carrasco, pp. 187194.

JIMÉNEZ FERNÁNDEZ， R. (2015): "Sobre el mantenimiento y pérdida de la /d/ intervocálica en el habla de Sevilla (sociolecto bajo)", León-Castro, M. y Zerva, A. (coords.): La variación en el español actual. Estudios dedicados al profesor Pedro Carbonero. Sevilla: Universidad de Sevilla, pp.193-209.

LEÓN-CASTRO GÓMEZ, M. (2016): "La presencia del andaluz en los medios de comunicación", Mancinas Chávez, R. (coord.); Actas del I Congreso Internacional Comunicación y Pensamiento, Sevilla: Ediciones Egregius, pp. 1583-1600.

LÓPEZ MORALES, H. (1989): Sociolingüistica, Madrid: Gredos.

MANJÓN-CABEZA CRUZ, A. (2018): "Creencias y actitudes de los jóvenes universitarios granadinos hacia las variedades cultas del español", Boletín de Filologia, tomo LIII, vol.2. Universidad de Chile, pp. 145-177.

MARCOS MARÍN, F. (1990): El comentario lingüístico. Metodología y práctica. Madrid: Cátedra

MÉNDEZ GARCÍA DE PAREDES, E. (2009): "La proyección social de la identidad lingüística de Andalucía. Medios de comunicación, enseñanza y política lingüística”. En Narbona Jiménez, A. (coord), La identidad lingüistica de Andalucia. Sevilla: Centro de Estudios Andaluces, pp. 213-319.

MORENO FERNÁNDEZ, F. (2005): Principios de sociolingüística y sociología del lenguaje. Barcelona: Ariel.

NARBONA JIMÉNEZ, A. (2009): "La identidad lingüistica de Andalucía", Narbona Jiménez, A. (coord.), La identidad lingüística de Andalucía. Sevilla: Centro de Estudios Andaluces, pp. 23-63.
NARBONA JIMÉNEZ, A. ET $A L$. (2003): El español hablado en Andalucía. Sevilla: Fundación José Manuel Lara.

REAL ACADEMIA ESPAÑOLA Y ASOCIACIÓN DE ACADEMIAS DE LA LENGUA ESPAÑOLA (RAE y ASALE) (2005): Diccionario Panhispánico de dudas. Madrid: Santillana.

REAL ACADEMIA ESPAÑOLA Y ASOCIACIÓN DE ACADEMIAS DE LA LENGUA ESPAÑOLA (RAE y ASALE) (2011): Nueva gramática de la lengua española. Fonética y fonología. Madrid: Espasa.

SANTANA MARRERO, J. (2018): "Creencias y actitudes de los jóvenes universitarios sevillanos hacia las variedades cultas del español", Boletín de Filología, tomo LIII, vol.2. Universidad de Chile, pp. 115-144.

SANTANA MARRERO, J. (en prensa): "Patrones sociolingüísticos de pronunciación en la ciudad de Sevilla: a propósito de seseo, ceceo y distinción", Patrones Sociolingüisticos del español hablado en la ciudad de Sevilla.

TERUEL RODRÍGUEZ, L. \& FERNÁNDEZ CABELLO-DELGADO (2005): "Andaluces en la telerrealidad: la audiencia a través del estereotipo del andaluz anónimo en televisión", Comunicar, $n^{\circ} 25,2$.

UREÑA RODRÍGUEZ, L. (2014): “España contra Andalucía, o la vigencia mediática de ciertos tópicos lingüísticos", Carriscondo Esquivel, Francisco Manuel (ed. y coord.): La lengua en el candelero. Repercusión mediática de asuntos lingüisticos. Vigo: Academia del Hispanismo, pp. 171204.

VAZ DE SOTO, J. M. (1995): "El andaluz en los "mass-media"", Actas 
del I Simposio Regional de Literatura Culta y Popular en Andalucía, Sevilla: Asociación Andaluza de Profesores de Español "Elio Antonio de Nebrija", pp. 77-86.

VILLENA PONSADA, J. A. (1997): "Sociolingüistica andaluza y socio- lingüística del andaluz: problemas y métodos", Narbona Jiménez, A. y Ropero Núñez, M. (eds.); Actas del congreso del habla andaluza, Sevilla: Seminario Permanente del Habla Andaluza, pp. 277-347. 